\title{
Investigation on Prospective Energy Power from Corncob Husk Biomass and its Biochars by Kinetic Parameters and Isoconversional Models
}

\author{
Carolina C. Bueno, Amanda A. D. Maia, Leandro C. de Morais and André H. Rosa* \\ Departamento de Engenharia Ambiental, Instituto de Ciência e Tecnologia, \\ Universidade Estadual Paulista "Júlio de Mesquita Filho" (UNESP), \\ Av. Três de Março, 511, 18087-180 Sorocaba-SP, Brazil
}

\begin{abstract}
The biofuel properties of biomass play an important role in achieving their utilization on agro-systems and industries. In this context the biomass waste of maize, corncob husk, and its biochars were taken into account to be investigated by thermogravimetric analysis, thermodynamic parameters for non-isothermal analyses using the Ozawa-Flynn-Wall kinetic isoconversional model in order to comprehend its possible fuels features. It was also investigated the compounds generated after pyrolysis and their relation with oxidation reactions for the safe-handling and storage. It was found that corncob husk biochar produced at $300{ }^{\circ} \mathrm{C}$ shows the best qualities as a solid biofuel, since it requires less energy input through pyrolysis to be produced. Finally, analysing the compounds generated and remained on the biochar's surface, by Fourier transform infrared spectroscopy (FTIR) analysis, biochars produced at low temperatures present one of the lowest features prone to oxidation reactions.
\end{abstract}

Keywords: corncob husk biomass, biochar, Ozawa-Flynn-Wall, kinetic parameters, autoignition

\section{Introduction}

The advance of bioenergy technology in the last decade has received attention due to its important influence on global warming and anthropogenic carbon dioxide emission. As biomass is able to capture atmosphere carbon in its biological structures while it grows, it is currently defined as a carbon-neutral fuel. ${ }^{1}$ Because of that, the exploration of biofuel properties of biomass plays an important role in sustainable agro-systems and agro-industries. Nevertheless the use of biomass not only has the potential usage as solid biofuels, but also has the potential use as carbon based byproducts obtained from biomass pyrolysis: biochar. Biochar is a carbon rich solid material produced by thermal decomposition of organic matter, generally biomass wastes. ${ }^{2}$ Biochar is also known as a multifunctional material in agro-systems which is employed primarily as a soil conditioner for immobilizing metals, improvement of drought resistance, recovery and fertilization of the soil. ${ }^{3}$ Both biomass and biochar can be used to design and fulfill a lifecycle favoring a competitive agricultural based world economy, inside farms and overall

*e-mail: ahrosa@ sorocaba.unesp.br agro and energy based industries. However, the energy content of biochar is also a safety matter, since the physical and chemisorption of oxygen during its storage can lead and induce to self-ignition at room or lower temperatures. ${ }^{4}$

It is known that maize is a promising crop (both final product and wastes). The USA corn production, just for grains production was estimated on $386.75 \mathrm{mmt}$ (million metric tons), while China and Brazil reach the numbers $21683.50 \mathrm{mmt}$ (estimated production). ${ }^{5}$ The final processing wastes of maize crops, as fuel form, are not widely known in the literature. Also, the literature does not discuss the thermal behavior of corncob husk, which is needed information for determining the energetic power as biomass and as biochar. In this context, the objective of this study was to quantitatively classify the thermal conversion features of corncob husk $(\mathrm{CH})$ biomass into biochar by means of ignition and burnout characteristics obtained through thermogravimetric analysis (TGA), as well as its thermodynamic parameters for non-isothermal analyses using the Ozawa-Flynn-Wall (OFW) kinetic isoconversional model. It was also investigated, by Fourier transform infrared spectrometry (FTIR), the volatile compounds which remain on the biochar surface in the presence of oxygen and nitrogen after its pyrolysis process 
in order to investigate the carbonized biomass stabilization during storage to achieve the safe-handling of biochar made of $\mathrm{CH}$ biomass. The resulting data may be used to enhance the understanding of these agricultural residues behavior as biofuels, since kinetic models are important to optimally design a pyrolysis system and, subsequently, provide a useful base for further application in local recovery of energy (e.g. farms), as well as its storage security under air and nitrogen atmospheres.

\section{Experimental}

\section{Biomass and biochar preparation}

The corncob husk residues used as biomass and for the biochar production were separated and stored into a wooden bay for prior natural drying for 7 days (Figure 1). After this period the biomass was collected and washed in tap water to remove dust and then dried in an oven with mechanical air circulation for $48 \mathrm{~h}$ at $80^{\circ} \mathrm{C}$. Subsequently, the dried samples were ground in a Willey mill (MA048) with a fixed rotation of $1730 \mathrm{rpm}$, followed by sieving (Solotest Sieve, 35 mesh).

In order to attain a better investigation of $\mathrm{CH}$ as a carbonized biomass, biochars were produced in a muffle furnace at nine different temperature regimes: 250,300 , $400,450,500,550,600,700$ and $800{ }^{\circ} \mathrm{C}$, designated, respectively, as $\mathrm{BC} 250, \mathrm{BC} 300, \mathrm{BC} 400, \mathrm{BC} 450, \mathrm{BC} 500$, $\mathrm{BC} 550, \mathrm{BC} 600, \mathrm{BC} 700$ and $\mathrm{BC} 800$. The thermal processing condition selected was a slow pyrolysis cycle with an increase of $5{ }^{\circ} \mathrm{C} \mathrm{min}^{-1}{ }^{6}$ The slow pyrolysis regime was selected as a standard procedure for this work in order to prioritize char production since it is known that the slow pyrolysis typically produces $35 \%$ char compared to $10 \%$ yield for the fast pyrolysis. ${ }^{7-9}$ The retention time of the samples produced by slow pyrolysis on targeted temperature was $120 \mathrm{~min}$. The samples were then naturally cooled at room temperature for $12 \mathrm{~h}$ (overnight). Subsequently, the samples were stored in labeled polypropylene bottles at room temperature until their use.

\section{Thermogravimetric analysis}

The $\mathrm{CH}$ biomass and its biochars samples were analyzed by thermogravimetric (TG) methods in order to determine the main parameters which may influence the thermal conversion and stabilization behavior under oxygen and nitrogen atmospheres. The combustion characteristics of corncob husk were determined on a simultaneous DSC-TG equipment, TA Instruments, model SDT Q600, nitrogen (99.99\% pure) and air (pure), gas at a $100 \mathrm{~mL} \mathrm{~min}^{-1}$ flow rate, at dynamic atmosphere and on alumina pans. The TG and DTG (derivative thermogravimetric) analyses for the biomass were performed at three different heating rates (5, 7.5 and $10{ }^{\circ} \mathrm{C}$ ), from 25 to $800{ }^{\circ} \mathrm{C}$, for each sample. The sample weight, for each experiment, was maintained at around $2.25 \pm 0.02 \mathrm{mg}$.

\section{Kinetic study}

The one-step global model assumes that biomass degradation processes results in a single reaction: ${ }^{10}$

Biomass $\stackrel{\mathrm{k}}{\longrightarrow}$ Water $+(\text { Volatiles }+ \text { Gases })_{1}+(\text { Biochar })_{1}$

where $\mathrm{k}$ is defined as the rate constant of reaction whose temperature dependence is expressed by the Arrhenius equation:

$\mathrm{k}=\mathrm{Ae} \mathrm{e}^{(-\mathrm{E} \alpha / \mathrm{RT})}$

where $\mathrm{E} \alpha$ is the apparent activation energy $\left(\mathrm{kJ} \mathrm{mol}^{-1}\right)$; $\mathrm{T}$ is the absolute temperature $(\mathrm{K})$; $\mathrm{R}$ is the universal gas constant $\left(8.31 \mathrm{~J} \mathrm{~K}^{-1} \mathrm{~mol}^{-1}\right)$; $\mathrm{A}$ is the pre-exponential factor $\left(\mathrm{s}^{-1}\right)$.

The rate of transformation from solid-state to volatile product is described by the following expression: ${ }^{11,12}$

$\frac{d_{\alpha}}{d_{t}}=k(T) f(\alpha)$

where $\alpha$ is the conversion degree of the process; $\mathrm{k}(\mathrm{T})$ is the time of process; $f(\alpha)$ is the rate constant and the reaction model.

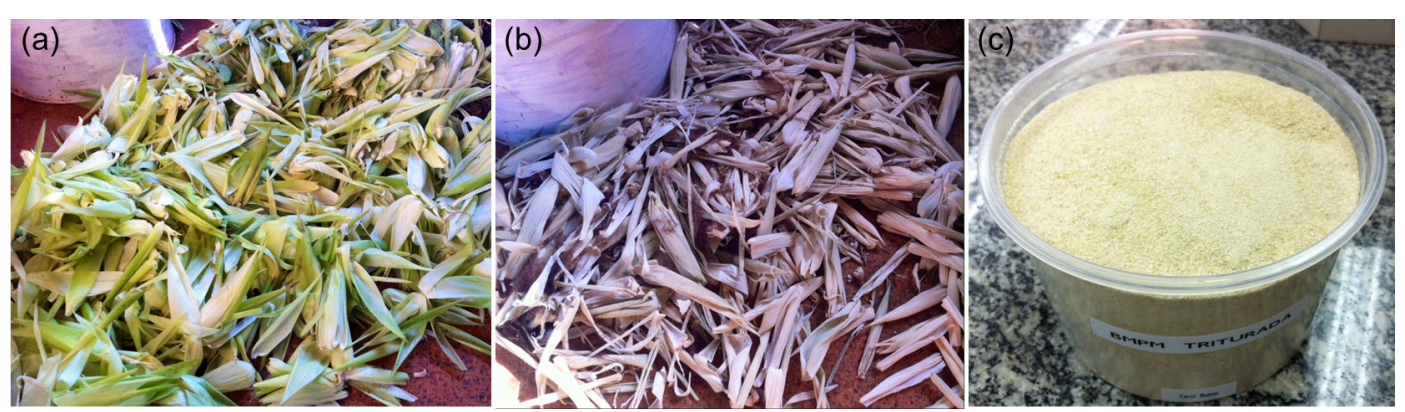

Figure 1. (a) Fresh corncob husk $(\mathrm{CH})$ residues used as biomass and for the biochar production; (b) $\mathrm{CH}$ biomass separated and stored into a wooden bay for prior natural drying for 7 days; (c) ground $\mathrm{CH}$ biomass. 
Conversion $(\alpha)$ represents the normalized form of weight loss data of decomposed sample and is defined as follows: ${ }^{13}$

$\alpha=\frac{\mathrm{m}_{\mathrm{i}}-\mathrm{m}_{\alpha}}{\mathrm{m}_{\mathrm{i}}-\mathrm{m}_{\mathrm{f}}}$

where $m_{i}$ is the initial mass of the sample; $m_{\alpha}$ is the actual mass; $\mathrm{m}_{\mathrm{f}}$ is the mass after combustion.

Combining equations 2 and 3 gives the fundamental expression of analytical methods to calculate kinetic parameters, on the basis of TG results, as follows:

$\frac{\mathrm{d}_{\alpha}}{\mathrm{d}_{\mathrm{t}}}=\mathrm{A} \times \mathrm{f}(\alpha) \times \mathrm{e}^{(-\mathrm{E} \alpha / \mathrm{RT})}$

The expression of the function $\mathrm{f}(\alpha)$ and its derivative $f(\alpha)$ are used for describing solid-state first order reaction:

$f(\alpha)=(1-\alpha)^{n}$

where $\mathrm{n}$ is the reaction order.

Substituting expression 6 into equation 5 gives the expression of reaction rate in the form:

$\frac{d_{\alpha}}{d_{t}}=A \times(1-\alpha)^{n} \times e^{(-E \alpha / R T)}$

For non-isothermal TG/DTG experiments at linear heating rate $\left(\beta=\mathrm{d}_{\mathrm{T}} / \mathrm{d}_{\mathrm{t}}\right)$, equation 7 can be written as:

$\frac{\mathrm{d}_{\alpha}}{\mathrm{d}_{\mathrm{t}}}=\frac{\mathrm{A}}{\beta} \times(1-\alpha)^{\mathrm{n}} \times \mathrm{e}^{(-\mathrm{E} \alpha / \mathrm{RT})}$

Equation 8 states the part of the biomass consumed at a precise period of time. Here, the activation energies were acquired from non-isothermal TG/DTG. The procedures used to determine kinetic parameters were non-isothermal and isoconversional Ozawa-Flynn-Wall (OFW) methods and, therefore, performed assessments at different heating rates were necessary.

\section{The Ozawa-Flynn-Wall method}

Non-isothermal thermogravimetric studies are a widely held method to investigate the kinetics and thermodynamics behavior of biomass. An isoconversional integral technique is a precise method for the estimation of the activation energy values without having information about the kinetic model of the reaction pathways. Therefore, the OFW kinetics isoconversional method was applied: ${ }^{14}$

$\ln (\beta)=\mathrm{C} \alpha-\frac{\mathrm{E} \alpha}{\mathrm{RT}}$ where $\beta$ is the heating rate; $\mathrm{E} \alpha$ is the apparent activation energy; $\mathrm{C} \alpha$ is the function of the conversion degree $\alpha ; \mathrm{R}$ is the universal gas constant $8.31 \mathrm{~J} \mathrm{~K}^{-1} \mathrm{~mol}^{-1}$; $\mathrm{T}$ is the absolute temperature $(\mathrm{K})$.

Three different values of heating rate $(\beta)$ were applied. In this work, the pre-exponential factor (A) and enthalpy $(\Delta \mathrm{H})$ (thermodynamic parameters; equations 10 and 11) were calculated using the $\mathrm{OFW}$ isoconversional method at an intermediate value of beta (i.e. $7.5^{\circ} \mathrm{C} \mathrm{min}^{-1}$ ).

$A=\beta E \alpha \exp \left(\frac{\frac{E \alpha}{R T m}}{R T m^{2}}\right)$

$\Delta \mathrm{H}=\mathrm{E} \alpha-\mathrm{RT}$

where $\mathrm{Tm}$ is the DTG peak temperature.

Ignition and burnout temperatures

The ignition temperatures (IT) of the biomass were determined from TG by two different methods: intersection method (IM) and deviation method (DM), for the three different heating rates $5,7.5$ and $10{ }^{\circ} \mathrm{C}$. The burnout temperatures (BOT) of the biomass were determined from the single peak of DTG curve, more specifically, the second peak. Both IT and BOT were calculated in order to investigate the effect caused by different heating rate values in these variables. These temperatures were calculated as indicated by $\mathrm{Lu}$ and $\mathrm{Chen}^{15}$ and the summary calculations can be seen in the Supplementary Information data.

Fourier transform infrared spectroscopy (FTIR)

The FTIR spectra for biochars samples were made using the pellet technique by mixing $0.1 \mathrm{mg}$ of dried biochar with $0.99 \mathrm{mg}$ of pre-dried and pulverized spectroscopic-grade $\mathrm{KBr}$ (Merck) and collected by a FTIR spectrometer Jasco $410^{\mathrm{TM}}$ operating in the spectral range from 4000 to $400 \mathrm{~cm}^{-1}$.

\section{Results and Discussion}

Thermogravimetric analysis of biomass in air and nitrogen

Figure 2a shows the thermal analysis for corncob husk biomass. For this sample it was verified that there was a small variation of mass with the increase of heating rate: 82,89 and $92 \%$ for air atmosphere. For $\mathrm{N}_{2}$ atmosphere the mass variation was more significant when the heating rate was increased: 67,76 and $87 \%$, for an initial temperature of breakdown at $120^{\circ} \mathrm{C}$, ending in $600{ }^{\circ} \mathrm{C}$. 
(a)

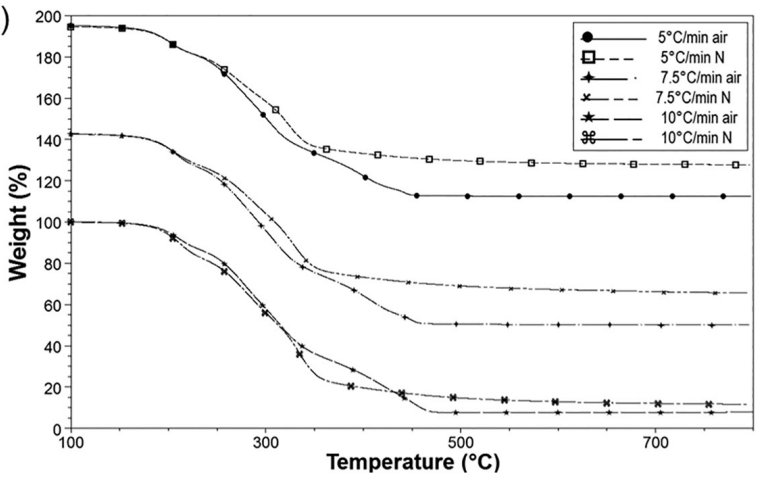

(b)

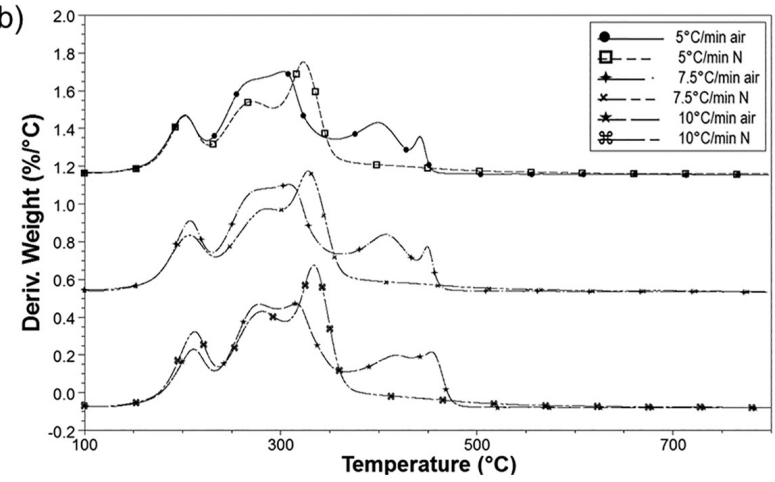

Figure 2. Distributions of (a) TG and (b) DTG of corncob husk. All curves compare the analysis in air and $\mathrm{N}_{2}$ atmospheres at the heating rates of 5; 7.5 and $10{ }^{\circ} \mathrm{C} \mathrm{min}^{-1}$.

In the DTG curve (Figure 2b) for $\mathrm{CH}$ biomass, three steps of degradation were verified, which the first happened quickly, in a single stage. The second and third reactions are characterized as overlapping reactions. In the first region of thermal decomposition (dehydration for pyrolysis; $<250{ }^{\circ} \mathrm{C}$ ), the first few changes that occur in biomass are related to the loss of water and a mild cellulose depolymerization ${ }^{16}$ and, therefore, the mass decreased only slightly. The release of water molecules (moisture) is highlighted by the first peak in the DTG curve. The second reaction is caused by the degradation of lignocellulose (ca. $300{ }^{\circ} \mathrm{C}$ ) and it is a route which shows a formation process of free radicals that are started by homolytic breakdown of chemical bonds. Free radicals that drive the process are initially formed by thermal action between structural inorganic impurities and the oxygen present in the biomass. An additional source of free radicals that can exist at the same time is due to the low atmospheric oxygen levels which may be present in the early stages of pyrolysis. ${ }^{16}$ At this stage, carboxyl and carbonyl groups are formed and subsequently cleaved to produce carbon dioxide and carbon monoxide. ${ }^{17}$ Between 250 and $350{ }^{\circ} \mathrm{C}$ the complete depolymerization of cellulose occurs, resulting in a great loss of mass because of volatilization and the creation of arrays of amorphous carbon. In this region of temperature (ca. $330{ }^{\circ} \mathrm{C}$ ) the first formation signs of aromatic carbons still occur and it can be one of the reasons for the overlapping of this step reaction. However, up to $350{ }^{\circ} \mathrm{C}$, polyaromatic graphene sheets begin to grow at the expense of the array of amorphous carbon. In addition, the intensity of the main peak changed only from 0.54 to $0.55 \% \mathrm{~min}^{-1}$ under atmospheric air, but under the $\mathrm{N}_{2}$ atmosphere it increased from 0.59 to $0.89 \% \mathrm{~min}^{-1}$.

In view of the temperature of the two main DTG peaks it is possible to identify the combustion efficiency of corncob husk: 308 and $328{ }^{\circ} \mathrm{C}$ for air and $\mathrm{N}_{2}$, respectively. Additionally, the $\mathrm{CH}$ biomass DTG analysis data also show that the corncob husk biomass is composed by a complex matrix because there are overlapping reactions sequels, which can be related to the intricacy of this biomass.

\section{Kinetic study}

The isoconversional method is the assessment of the dependency of the real E $\alpha$ needed on the conversion or temperature evolvement. The usage of this dependency for assembly kinetic calculations becomes necessary in order to explore the mechanisms involved in thermal breakdown. ${ }^{14} \mathrm{In}$ other words, in isoconversional kinetic analysis, the biomass degree of conversion $(\alpha)$ is expected to be constant, and also the ratio of reaction depends totally on the temperature of reaction (T).$^{18}$ In this context, Figure 3 represents the curves of conversion degree $v s$. temperature at different heating rates, 5, 7.5 and $10{ }^{\circ} \mathrm{C} \mathrm{min}^{-1}$ for corncob husks (a) in air atmosphere and (b) in $\mathrm{N}_{2}$ atmosphere. One predominant stage can be seen in the progression of the systems and, thus, $\mathrm{CH}$ thermal degradation is described as a homogeneous process. Commonly, as the heating rate slows, the temperature at which conversion occurs is lower. ${ }^{19}$

Corncob husk is an herbaceous biomass material. Therefore, the first stage of conversion, the portion between the temperatures 80 and $200{ }^{\circ} \mathrm{C}$ can be linked with thermal degradation of cellulose. Information from TG and DTG curves in the breakdown range of $0.1<\alpha<0.9$ were used to determine the kinetic parameters of the process in all subsequent calculations. Figure 4 represents $\ln \beta$ versus $\alpha(1 / \mathrm{T})$ by means of TG curves present in Figure 2.

The value of the $\mathrm{E} \alpha$ declines with the intensification of the conversion processes. Thus, the activation energy of the $\mathrm{CH}$ biomass for the extreme alpha values of 25 and $95 \%$ are 2.79 and $67.17 \mathrm{~kJ} \mathrm{~mol}^{-1}$, respectively, for air atmosphere; and 7.63 and $71.69 \mathrm{~kJ} \mathrm{~mol}^{-1}$ for $\mathrm{N}_{2}$ atmosphere, respectively. The difference between the activation energies is due to responses of the solid-state samples, which are not 

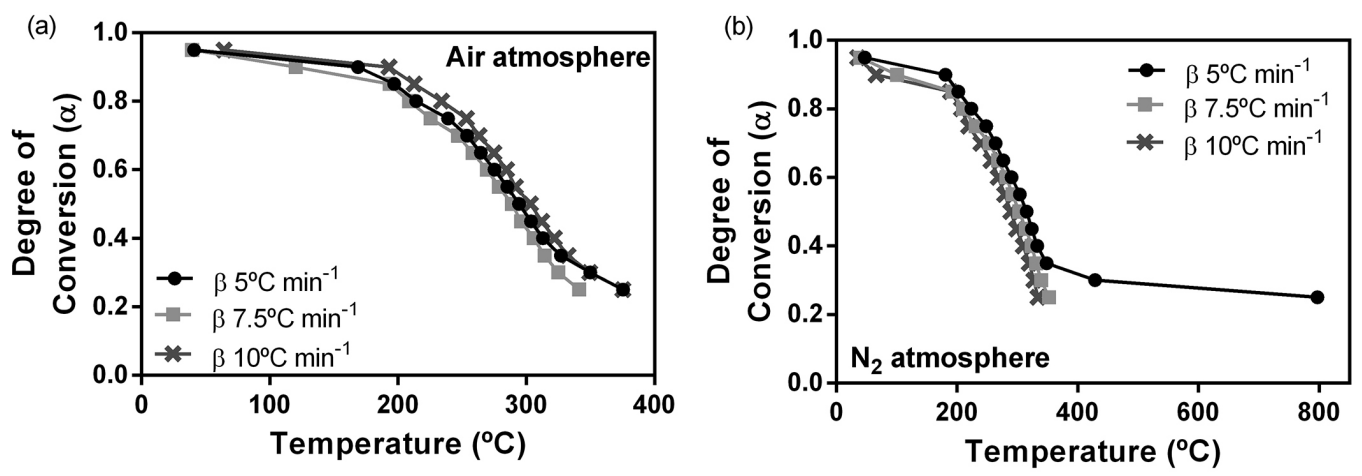

Figure 3. Curves of conversion degree $v s$. temperature at different heating rates and different atmospheres (a) for $\mathrm{CH}$ at air atmosphere; (b) for $\mathrm{CH}_{\text {at }} \mathrm{N}_{2}$ atmosphere. One predominant stage can be seen in the progression, thereby illustrating a homogeneous process.

(a)

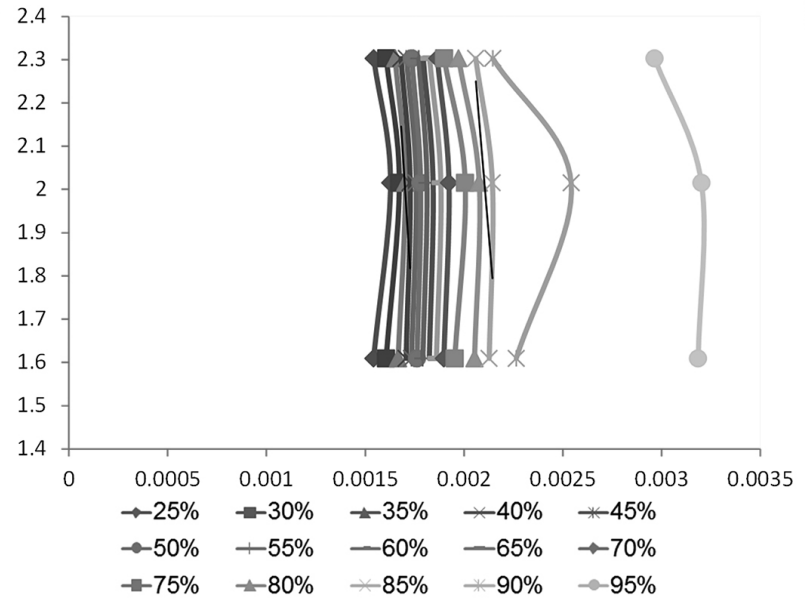

(b) 2.4

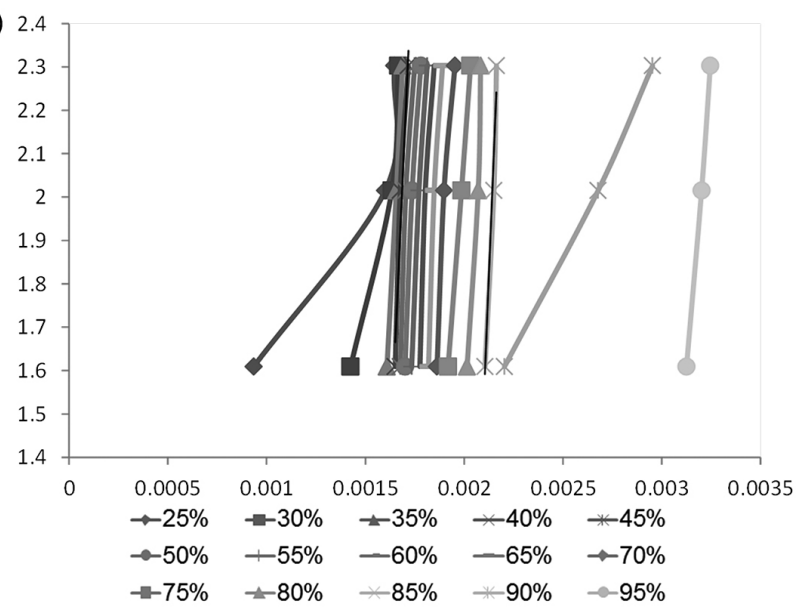

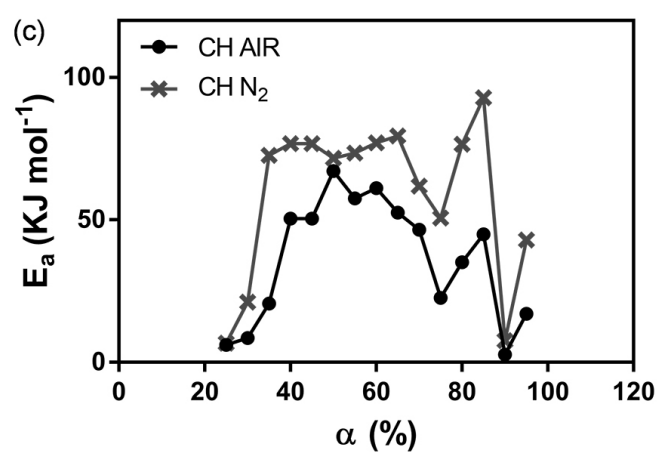

Figure 4. The Ozawa-Flynn-Wall isoconversion method applied to the thermal processing TG data of (a) $\mathrm{CH}$ at air atmosphere; (b) $\mathrm{CH}$ at $\mathrm{N}_{2}$ atmosphere in open pans within 25-95\% of conversion and (c) changes of activation energy during biomass breakdown process for both atmospheres studied. The apparent activation energy varies with increasing conversion rates and indicated volatiles degradation approximately at an $\alpha 50-85 \%$ and is directly related with the reactivity of the $\mathrm{CH}$ biomass.

decomposed in a simple one-step mechanism. In contrast, this decomposition occurs and follows a complex multi-step reaction ${ }^{20}$ because of the biomass complexity, mainly at lower conversion stages. For that reason it is commonly accepted that values of the activation energy on the range of $60-120 \mathrm{~kJ} \mathrm{~mol}^{-1}$ are reasonably low and indicates that the higher values of activation energy is required to decompose biomass with greater lignin amounts. ${ }^{21}$ For lignocellulosic biomass the activation energy can vary from
80 to $200 \mathrm{~kJ} \mathrm{~mol}^{-1}$ for hemicellulose, $195-286 \mathrm{~kJ} \mathrm{~mol}^{-1}$ for cellulose and $18-65 \mathrm{~kJ} \mathrm{~mol}^{-1}$ for lignin.

The first activation energy value observed was small due to cleavage of weak chemical bonds and the removal of biomass' volatile constituents and also because at the start of the thermal breakdown all the strong bonds of the biomass were not cleaved. ${ }^{22}$ Figure $4 \mathrm{c}$ represents the values of E $\alpha$ during the heating process at both studied atmospheres. If the variance between $\mathrm{E} \alpha$ values is minor, 
smaller is the energy used at thermal conversion process of this biomass. ${ }^{23}$ It is also important to highlight that the chemical stability of a material is directly proportional to the value of activation energy. ${ }^{13}$ Since the pre-exponential factors are directly related to the biomass structures, ${ }^{23}$ Table 1 shows the kinetic parameters at the point of maximum conversion for corncob husk for the three heating rates analyzed.

The values of first order pre-exponential factors for $\mathrm{CH}$ biomass ranged from $10^{-2}$ to $10^{5} \mathrm{~s}^{-1}$ and $10^{0}$ to $10^{9} \mathrm{~s}^{-1}$, for air and $\mathrm{N}_{2}$ atmospheres, respectively. The low pre-exponential factors $\left(<10^{9} \mathrm{~s}^{-1}\right)$ may indicate a surface feedback of corncob husk biomass, as well as a tight complex, and difficulty to breakdown..$^{24}$ The lower values of $\mathrm{A}$ and $\mathrm{E} \alpha$ found in $\mathrm{CH}$ biomass indicate a quicker and easier degradation effect of this biomass, at the respective degrees of conversion, when compared with biomass of non-lignocellulosic origin. ${ }^{25}$

\section{Ignition and burnout temperatures}

Ignition temperature (IT) is defined as the smallest temperature at which a fuel ignites spontaneously in an environment deprived of an external source of ignition. ${ }^{26}$ The IT is greatly associated with safety in storage and delivery when coal or char is employed as a fuel in industry. On the other hand, the burnout temperature (BOT) of a fuel is an indicator of its reaction degree. ${ }^{27}$ Therefore, the higher the BOT value, the smaller amount of the combustible components left in the fuel; i.e., the BOT states the temperature at which the fuel is virtually fully consumed.

Figure 5a shows the ignition and burnout temperatures obtained from IM and DM CH biomass. The IT of corncob husk calculated by IM ranged from 218 to $223{ }^{\circ} \mathrm{C}$ for air atmosphere and from 235 to $240{ }^{\circ} \mathrm{C}$ for $\mathrm{N}_{2}$ atmosphere. The IT did not increase notably with the heating rate. Using the DM method, the IT ranged from 112 to $220^{\circ} \mathrm{C}$. The difference of IT values measured by IM and DM is consistent with the fact that the IM method is based on cellulose reaction, while DM is based on lignin hemicellulose, which is more reactive than cellulose and lignin. ${ }^{28,29}$ Once biomass was ignited, the procedure initiates with the combustion of hemicellulose and volatile matter. In this context, the BOT of corncob husk biomass was between 341 and $352^{\circ} \mathrm{C}$ for air atmosphere and, for $\mathrm{N}_{2}$ atmosphere, between 354 and $365^{\circ} \mathrm{C}$. When biomass was ignited, the combustion of volatile matter ruled the chemical reactions. The primary step of biomass combustion is related to the homogeneous reaction. When the chemical reactions shift to burnout, char combustion takes over, and this secondary step reaction dynamics is consequence of a heterogeneous reaction. ${ }^{15}$ Therefore, the heating rate has more impact on changing BOT than on IT.

In Table 2, the equations of the regression lines and their coefficients of determination ( $\mathrm{R}^{2}$ values) for the profiles of the IT and BOT are given. The values calculated for corncob husk, for both IM and DM methods, are characterized by

Table 1. Kinetic parameters of corncob straw biomass in air and $\mathrm{N}_{2}$ atmosphere

\begin{tabular}{|c|c|c|c|c|c|c|}
\hline \multirow{2}{*}{$\alpha / \%$} & \multicolumn{3}{|c|}{$\mathrm{CH}$ air atmosphere } & \multicolumn{3}{|c|}{$\mathrm{CH} \mathrm{N}_{2}$ atmosphere } \\
\hline & $\mathrm{E} \alpha /\left(\mathrm{kJ} \mathrm{mol}^{-1}\right)$ & $\Delta \mathrm{H}$ & $\mathrm{A} / \mathrm{s}^{-1}$ & $\mathrm{E} \alpha /\left(\mathrm{kJ} \mathrm{mol}^{-1}\right)$ & $\Delta \mathrm{H}$ & $\mathrm{A} / \mathrm{s}^{-1}$ \\
\hline 25 & 6.134 & $6.13 \times 10^{3}$ & $3.04 \times 10^{-2}$ & 6.782 & $6.78 \times 10^{3}$ & $3.61 \times 10^{-2}$ \\
\hline 30 & 8.562 & $8.56 \times 10^{3}$ & $7.55 \times 10^{-2}$ & 21.132 & $2.11 \times 10^{4}$ & $2.02 \times 10^{0}$ \\
\hline 35 & 20.607 & $2.06 \times 10^{4}$ & $2.29 \times 10^{0}$ & 72.651 & $7.26 \times 10^{4}$ & $3.46 \times 10^{5}$ \\
\hline 40 & 50.487 & $5.05 \times 10^{4}$ & $3.06 \times 10^{3}$ & 76.782 & $7.68 \times 10^{4}$ & $6.47 \times 10^{5}$ \\
\hline 45 & 50.487 & $5.05 \times 10^{4}$ & $3.82 \times 10^{3}$ & 76.782 & $7.68 \times 10^{4}$ & $8.70 \times 10^{5}$ \\
\hline 50 & 67.163 & $6.72 \times 10^{4}$ & $2.12 \times 10^{5}$ & 71.687 & $7.17 \times 10^{4}$ & $3.89 \times 10^{5}$ \\
\hline 55 & 57.528 & $5.75 \times 10^{4}$ & $2.99 \times 10^{4}$ & 73.447 & $7.34 \times 10^{4}$ & $8.16 \times 10^{5}$ \\
\hline 60 & 61.166 & $6.12 \times 10^{4}$ & $9.11 \times 10^{4}$ & 77.066 & $7.71 \times 10^{4}$ & $2.58 \times 10^{6}$ \\
\hline 65 & 52.596 & $5.26 \times 10^{4}$ & $1.57 \times 10^{4}$ & 79.476 & $7.95 \times 10^{4}$ & $7.24 \times 10^{6}$ \\
\hline 70 & 46.555 & $4.66 \times 10^{4}$ & $4.65 \times 10^{3}$ & 61.870 & $6.19 \times 10^{4}$ & $1.72 \times 10^{5}$ \\
\hline 75 & 22.622 & $2.26 \times 10^{4}$ & $1.21 \times 10^{1}$ & 50.650 & $5.06 \times 10^{4}$ & $2.03 \times 10^{4}$ \\
\hline 80 & 35.168 & $3.52 \times 10^{4}$ & $5.61 \times 10^{2}$ & 76.520 & $7.65 \times 10^{4}$ & $3.53 \times 10^{7}$ \\
\hline 85 & 44.952 & $4.49 \times 10^{4}$ & $1.26 \times 10^{4}$ & 92.814 & $9.28 \times 10^{4}$ & $6.48 \times 10^{9}$ \\
\hline 90 & 2.790 & $2.79 \times 10^{3}$ & $2.38 \times 10^{-2}$ & 7.628 & $7.63 \times 10^{3}$ & $3.59 \times 10^{-1}$ \\
\hline 95 & 17.034 & $1.70 \times 10^{4}$ & $6.95 \times 10^{1}$ & 42.966 & $4.30 \times 10^{4}$ & $3.82 \times 10^{6}$ \\
\hline
\end{tabular}

$\mathrm{CH}$ : corncob husk; $\alpha$ : conversion; E $\alpha$ : apparent activation energy; $\Delta \mathrm{H}$ : enthalpy; A: pre-exponential factor. 
(a)

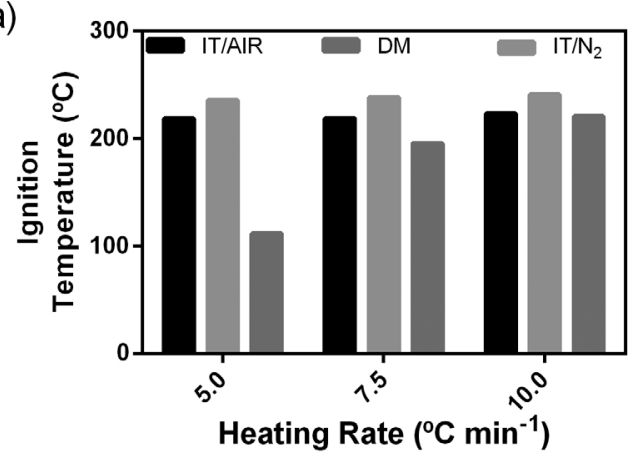

(b)

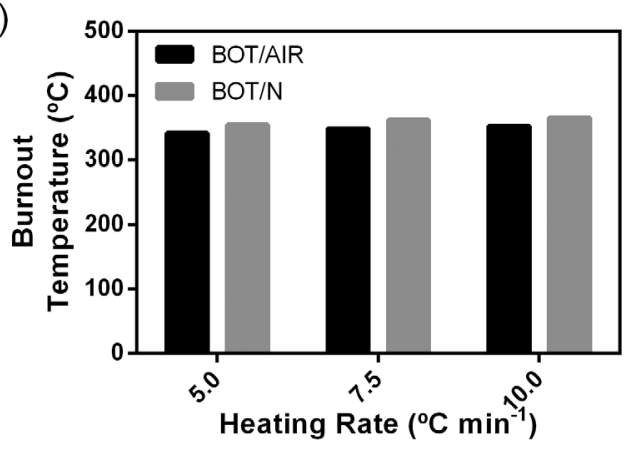

(c)

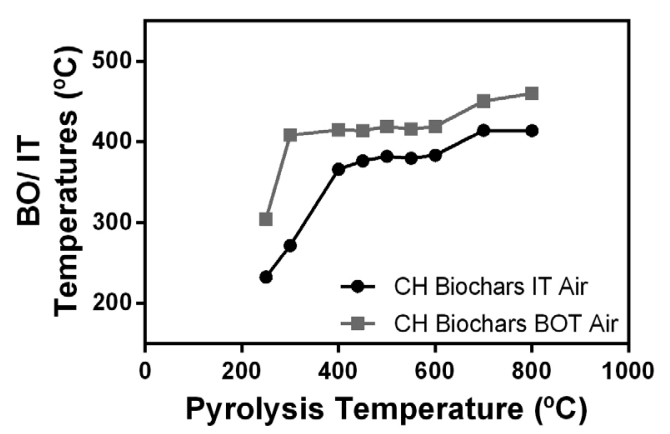

Figure 5. Ignition (IT) and burnout temperatures (BOT) of corncob husk by TG analysis: (a) IT calculated by intersection and deviation method; (b) BOT calculated by intersection method; (c) BOT and IT for $\mathrm{CH}$ biochars calculated by intersection method.

Table 2. Regression lines and coefficients of $\mathrm{CH}$ biomass ignition and burnout temperatures

\begin{tabular}{|c|c|c|c|c|}
\hline \multirow{2}{*}{ Method } & \multicolumn{2}{|c|}{ Regression line } & \multicolumn{2}{|c|}{$\mathrm{R}^{2}$} \\
\hline & Air & $\mathrm{N}_{2}$ & Air & $\mathrm{N}_{2}$ \\
\hline \multicolumn{5}{|c|}{ Ignition temperature } \\
\hline IM & $y=6.068 x+343.7$ & $y=2.190 x+344.3$ & 0.9933 & 0.9683 \\
\hline $\mathrm{DM}$ & \multicolumn{2}{|c|}{$y=-21.72 x+338.9$} & \multicolumn{2}{|c|}{0.9108} \\
\hline \multicolumn{5}{|c|}{ Burnout temperature } \\
\hline IM & $y=6.068 x+343.7$ & $\mathrm{y}=2.190 \mathrm{x}+344.3$ & 0.9933 & 0.9683 \\
\hline
\end{tabular}

IM: intersection method; DM: deviation method; $\mathrm{R}^{2}$ : coefficient of determination.

a linear relationship $\left(\mathrm{R}^{2}\right)$ and also, they show identical behavior.

The analysis of IT and BOT were also made on nine different biochars produced from corncob straw. By means of ignition temperatures, $\mathrm{BC} 250$ and $\mathrm{BC} 300$ show the best values for biofuels application. Low ignition temperatures of 271.73 and $323.34^{\circ} \mathrm{C}$ indicate that $\mathrm{BC} 250$ requires lower energy input to start the material ignition. BC400 to BC600 fairly maintains the stability values for IT, ranging from 367 to $383{ }^{\circ} \mathrm{C}$. Burnout temperatures indicate that $\mathrm{BC} 300$ is the most suitable material for biofuel application, because this temperature is the lowest pyrolysis temperature with the higher BOT value and lower IT value. In other words, BC300 requires less energy during pyrolysis to be produced; finally, its combustible components remaining in the fuel are almost completely consumed during the burn. These results suggest that the presence of amorphous carbon, as shown in TG/DTG analysis is an indicator for worthy carbon based biofuels.

Compounds generated and remained on the biochar's surface - safe-handling and storage

The FTIR spectra point out the signature of compounds generated during the pyrolysis process. As shown in Figure 6, the main components were $\mathrm{CO}_{2}, \mathrm{CO}, \mathrm{CH}_{4}, \mathrm{CH}_{3} \mathrm{OH}$, phenols and $\mathrm{C}=\mathrm{O}$ (carbonyl groups). The organic oxygen in the samples is evolved during the pyrolysis according to the level of hemicelluloses and lignin breakdown. The main wave numbers considered on the FTIR peaks of the biochars for air and nitrogen atmospheres were: $\mathrm{CO}_{2}: 2358 \mathrm{~cm}^{-1}$, CO: $2181 \mathrm{~cm}^{-1} ; \mathrm{CH}_{4}: 3022 \mathrm{~cm}^{-1} ; \mathrm{CH}_{3} \mathrm{OH}: 1046 \mathrm{~cm}^{-1}$; phenols: $1100 \mathrm{~cm}^{-1}$; and $\mathrm{C}=\mathrm{O}: 1740 \mathrm{~cm}^{-1}$. 
By the analysis of the generated absorbance is observed how much energy was absorbed in a specific wavelength region. Overall is noted that the pyrolysis atmosphere is an important parameter, because peak intensities are greater under air atmosphere and demonstrate the more oxidized status of the sample, thus leading to more potential safety and storage risks. All samples showed non-linear relationship with pyrolysis temperature. Particularly, the sample BC550 presents the lowest levels of each evolved pyrolytic product investigated on the structure of this biochar, even under inert atmosphere. Subsequently, BC450 appeared to be more sensitive to oxidation reactions because it is known that physical adsorption of oxygen is followed by chemical adsorption. ${ }^{30}$ The $\mathrm{BC} 450$ seems to not be suited for safe handling and storage in uncontrolled environments, whether for use in fuels or agriculture, because its intrinsically oxidized nature made this material more prone to auto-ignition, based on the evolved pyrolytic products in its chemical structure.

However, when the results of IT and BOT temperatures, as well as TG and kinetics parameters, are combined with the results shown on Figure 6, they converge to a possible suggestion about the $\mathrm{BC} 300$ : $\mathrm{BC} 300$ required less energy during pyrolysis to be produced, less external energy input to start ignition and its combustible components left in the fuel are almost completely consumed in the burn. This material also presents one of the lowest sensibility features prone to oxidation reaction, especially under nitrogen atmosphere. Finally, BC250, BC300 and BC550 appeared to be the more inert materials to handle and store. (a)

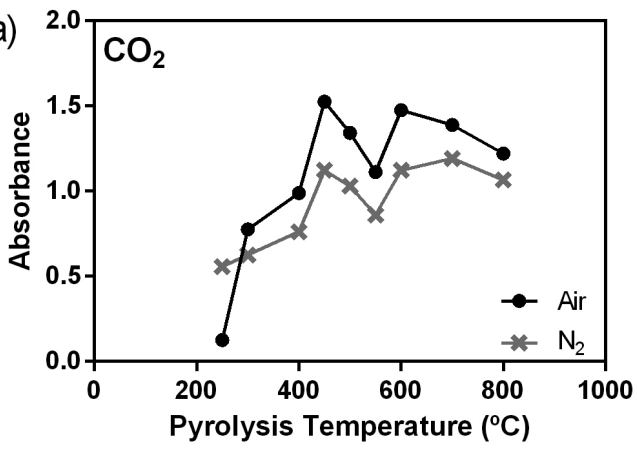

(c)

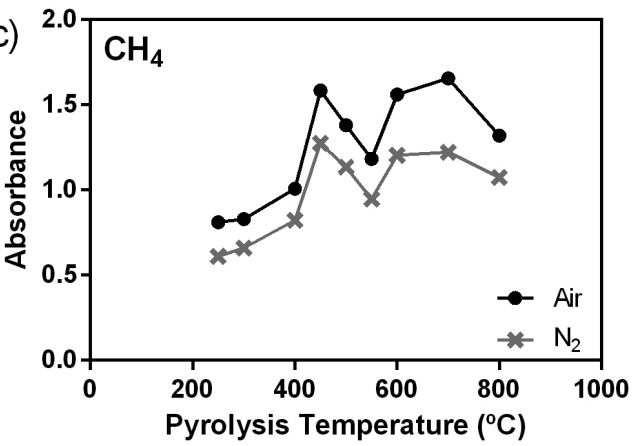

(e)

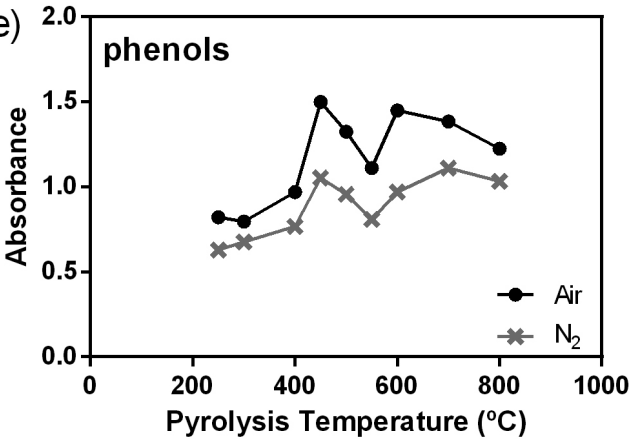

(b)

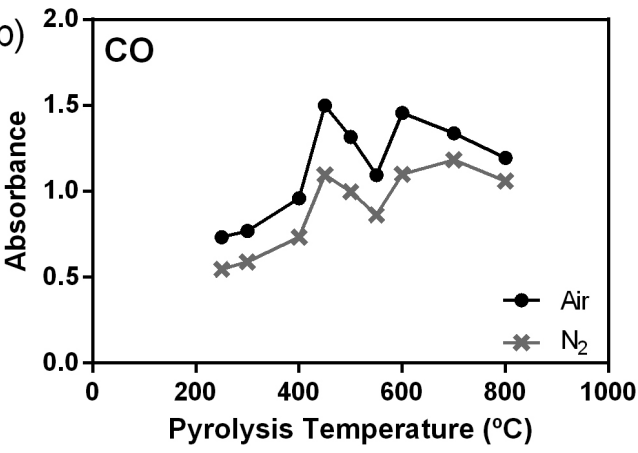

(d)

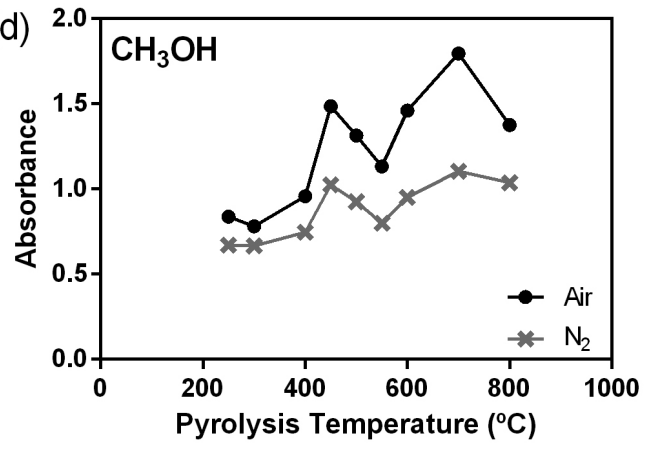

(f)

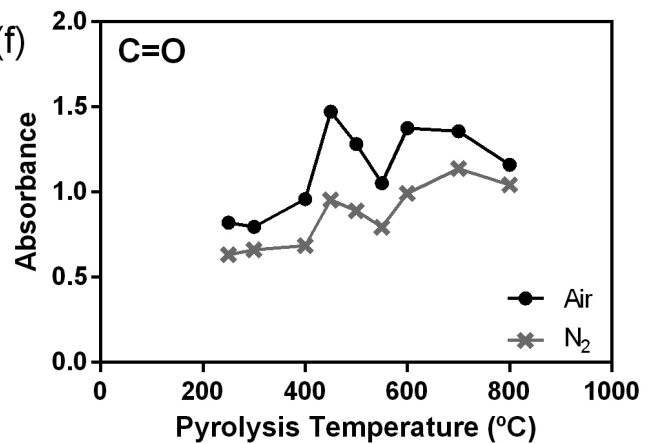

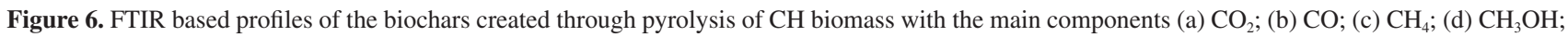
(e) phenols; (f) $\mathrm{C}=\mathrm{O}$. 


\section{Conclusions}

Observing the ignition temperatures for $\mathrm{CH}$ biomass is concluded that corncob husk biomass is a loose complex, and therefore, the decomposition of this biomass does not require a lot of energy input. Through the ignition and burnout temperatures, $\mathrm{BC} 300$ shows the best qualities as a biofuel, because compared to the other temperatures its production required less energy during pyrolysis. The formation of crystalline sheets of carbon as suggested by the TG analysis seems to be an important feature for pore development on biochar, directly influencing the propensity of the material to be indicated as fuel.

Regarding material safety in biofuel use, BC250, $\mathrm{BC} 300$ and BC550 appeared to be the more inert materials to handle and store, since their propensity for oxidation reactions appeared to be the lowest. In contrast, BC450 appeared to be more prone to oxidation reactions, forming carbon-oxygen complexes and oxygenated carbon-species given the evolved pyrolytic products identified in its chemical structure, which leads this particular material to be more prone to self-heating and auto-ignition, not being safe for storage and handling.

\section{Supplementary Information}

Supplementary data are available free of charge at http://jbcs.sbq.org.br as PDF file.

\section{Acknowledgments}

The authors would like to thank the Fundação de Amparo à Pesquisa do Estado de São Paulo (FAPESP), Proc. 2013/08373-0, 2013/24168-8 and 2016/08215-4; CNPq for the scholarship and financial support; and Prof Nilson Cruz of Laboratory of Technological Plasmas (LaPTec, UNESP, Sorocaba) for granting the FTIR equipment for the biochar analysis.

\section{References}

1. Azar, C.; Lindgren, K.; Larson, E.; Möllersten, K.; Clim. Change 2006, 74, 47.

2. Mao, J. D.; Johnson, R. L.; Lehmann, J.; Olk, D. C.; Neves, E. G.; Thompson, M. L.; Schmidt-Rohr, K.; Environ. Sci. Technol. 2012, 46, 9571.

3. Hao, F.; Zhao, X.; Ouyang, W.; Lin, C.; Chen, S.; Shan, Y.; Lai, X.; Agron. J. 2013, 105, 773.

4. Bradbury, A. G. W.; Shafizadeh, F.; Combust. Flame 1980, 37 , 85
5. http://usda.mannlib.cornell.edu/usda/current/CropProdSu/ CropProdSu-01-12-2017.pdf, accessed in April 2017.

6. Ben, H.; Ragauskas, A. J.; Bioresour. Technol. 2013, 147, 577.

7. Demirbas, A.; J. Anal. Appl. Pyrolysis 2004, 72, 243.

8. Demirbas, A.; J. Anal. Appl. Pyrolysis 2005, 73, 39.

9. Carrier, M.; Hardie, A. G.; Uras, U.; Gorgens, J.; Knoetze, J. P.; J. Anal. Appl. Pyrolysis 2012, 96, 24.

10. Koufopanos, C. A.; Papayannakos, N.; Maschio, G.; Lucchesi, A.; Can. J. Chem. Eng. 1991, 69, 907.

11. Jankovic, B.; Chem. Eng. J. 2008, 139, 128.

12. Ounas, A.; Aboulkas, A.; El Harfi, K.; Bacaoui, A.; Yaacoubi, A.; Bioresour. Technol. 2011, 102, 11234.

13. Domingos, M. A. A.; de Morais, L. C.; Bioresour. Technol. 2016, 204, 157.

14. Vyazovkin, S.; Sbirrazzuoli, N.; Macromol. Rapid Commun. 2006, 27, 1515.

15. Lu, J.-J.; Chen, W.-H.; Appl. Energy 2015, 160, 49.

16. Amonette, J. E.; Joseph, S. In Biochar for Environmental Managment: Science and Technology, $1^{\text {st }}$ ed.; Lehmann, J.; Joseph, S., eds.; Earthscan: Washington, DC, USA, 2009, ch. 3.

17. Brennan, J. K.; Thomson, K. T.; Gubbins, K. E.; Colloids Surf., A 2001, 97, 264.

18. Islam, M. A.; Auta, M.; Kabir, G.; Hameed, B. H.; Bioresour. Technol. 2016, 200, 335.

19. Salla, J. M.; Morancho, J. M.; Cadenato, A.; Ramis, X.; J. Therm. Anal. Calorim. 2003, 72, 719.

20. Heydari, M.; Rahman, M.; Gupta, R.; Int. J. Chem. Eng. 2015, $2015,1$.

21. Burhenne, L.; Messmer, J.; Aicher, T.; Laborie, M.-P.; J. Anal. Appl. Pyrolysis. 2013, 101, 177.

22. Gasparovic, L.; Labovsky, J.; Markos, J.; Jelemensky, L.; Chem. Biochem. Eng. Q. 2012, 26, 45.

23. Vlaev, L. T.; Georgieva, V. G.; Genieva, S. D.; J. Therm. Anal. Calorim. 2007, 88, 805.

24. Turmanova, S. C.; Genieva, S. D.; Dimitrova, A. S.; Vlaev, L. T.; eXPRESS Polym. Lett. 2008, $2,133$.

25. Santos, C. M.; Dweck, J.; Viotto, R. S.; Rosa, A. H.; de Morais, L. C.; Bioresour. Technol. 2015, 196, 469.

26. Jiang, T. L.; Chen, W. S.; Tsai, M. J.; Chiu, H. H.; Combust. Flame 1995, 103, 221.

27. Du, S.-W.; Chen, W.-H.; Lucas, J. A.; Energy 2010, 35, 576.

28. Arias, B.; Pevida, C.; Rubiera, F.; Pis, J. J.; Fuel 2008, 87, 2753.

29. Mortari, D. A.; Ávila, L.; dos Santos, A. M.; Crnkovic, P. M.; Therm. Eng. 2010, 9, 81.

30. Candeliera, K.; Dibdiakovab, J.; Vollea, G.; Rousseta, P.; Thermochim. Acta 2016, 644, 33.

Submitted: February 14, 2017

Published online: April 17, 2017 